NOTE

\title{
Extraction of benthic microalgal pigments for HPLC analyses
}

\author{
Evelyne Buffan-Dubau*, Kevin R. Carman
}

Dept of Biological Sciences, Louisiana State University, Baton Rouge, Louisiana 70803, USA

\begin{abstract}
Studies of microphytobenthic communities often require the use of HPLC pigment analysis. The first step of such chromatographic analyses consists of extracting pigments. Three methodological points relative to sedimentary pigment extraction for subsequent HPLC analyses were examined using sediment samples from a mudflat. We studied effects of both sample freeze-drying prior to extraction, and 2 extraction solvents $(100 \%$ acetone and buffered methanol). We also examined the influence of extraction time on pigment recovery. Freeze-drying significantly improved pigment extraction from mud samples. Acetone yielded significantly better recoveries of pheopigments, but (in freezedried sediment) acetone and buffered methanol did not differ significantly in their extraction of chl a or carotenoids. Longtime extraction (up to $24 \mathrm{~h}$ ) improved recovery of chl $a$, but not other pigments.
\end{abstract}

KEY WORDS: Sediments $\cdot$ Pigments $\cdot$ Extraction $\cdot$ HPLC

Resale or republication not permitted without written consent of the publisher

Pigment studies provide useful information about oceanic plant communities. Measurements of chlorophyll a (chl a) in surface waters and superficial sediments provide estimates of plant biomass and productivity whereas carotenoid pigments are commonly used as taxonomic biomarkers to characterise planktonic and benthic microalgal communities (Riaux-Gobin et al. 1987, Plante-Cunny et al. 1993, Pinckney et al. 1994). Such studies are now often handled by the use of HPLC pigment analyses (Cariou-Le Gall \& Blanchard 1995, Jeffrey et al. 1997, Brotas \& Plante-Cunny 1998). HPLC analysis techniques allow separation of pigments prior to spectrophotometric and/or fluorimetric measurements, avoiding interference among pigments.

*Present address: Laboratoire d'Océanographie Biologique, Station Marine d'Arcachon, Université Bordeaux 1, 2 Rue du Professeur Jolyet, 33120 Arcachon, France.

E-mail: e.buffan-dubau@biocean.u-bordeaux.fr
Although HPLC techniques have been applied to the study of natural microphytobenthic communities (RiauxGobin et al. 1987, Plante-Cunny et al. 1993, Cariou-Le Gall \& Blanchard 1995, Brotas \& Plante-Cunny 1998, Paterson et al. 1998, Lucas \& Holligan 1999, BuffanDubau \& Carman 2000), studies of protocols adapted to sediment sample analysis are rare (Riaux-Gobin et al. 1987, Plante-Cunny et al. 1993, Brotas \& Plante-Cunny 1996). The first step in chromatographic analysis consists of performing a qualitatively and quantitatively efficient extraction of pigments from samples into a compatible solvent. Pigment extraction efficiency can be influenced by many factors including the choice of the extraction solvent, based on its penetration power and solvation properties, the duration of extraction, and treatments applied to samples prior to extraction (Jeffrey et al. 1997). These points remain a matter of debate for sedimentary pigment analyses. Pure acetone and buffered methanol have been recommended as extraction solvents for phytoplankton pigment analyses (Wright et al. 1991, Jeffrey et al. 1997), and are both commonly used for microphytobenthos studies without explicit consideration of extraction efficiency (Riaux-Gobin et al. 1987, Plante-Cunny et al. 1993, Cariou-Le Gall \& Blanchard 1995, Buffan-Dubau et al. 1996, Brotas \& Plante-Cunny 1998, Paterson et al. 1998, Lucas \& Holligan 1999). Durations of extractions reported in the literature vary from a few minutes (Brotas \& Plante-Cunny 1998) to $24 \mathrm{~h}$ (Cariou-Le Gall \& Blanchard 1995). While freeze-drying of sediment samples prior to extraction has been proposed, RiauxGobin et al. (1987) found that freeze-drying reduced efficiency of sedimentary pigment extraction whereas Plante-Cunny et al. (1993) observed that it improved reproducibility of results. Accordingly, the purpose of this work was to test these methodological issues. This note describes how choice of solvent, freeze-drying, and duration of extraction influenced our extraction efficiency. 
Materials and methods. The study site, located near Cocodrie, Louisiana, USA $\left(30^{\circ} 15^{\prime} \mathrm{N}, 91^{\circ} 21^{\prime} \mathrm{W}\right)$, is a mudflat surrounded by stands of Spartina alterniflora Loisel. Sediment samples were collected in June 1997 (extraction-duration experiment) and June 1999 (solvent and freeze-drying experiment). Sediment cores were hand collected using butyrate tubing $(3.5 \mathrm{~cm}$ i.d.). Surficial sediment (top $1 \mathrm{~cm}$ ) was collected, frozen on liquid nitrogen, and stored at $-80^{\circ} \mathrm{C}$. Further details of
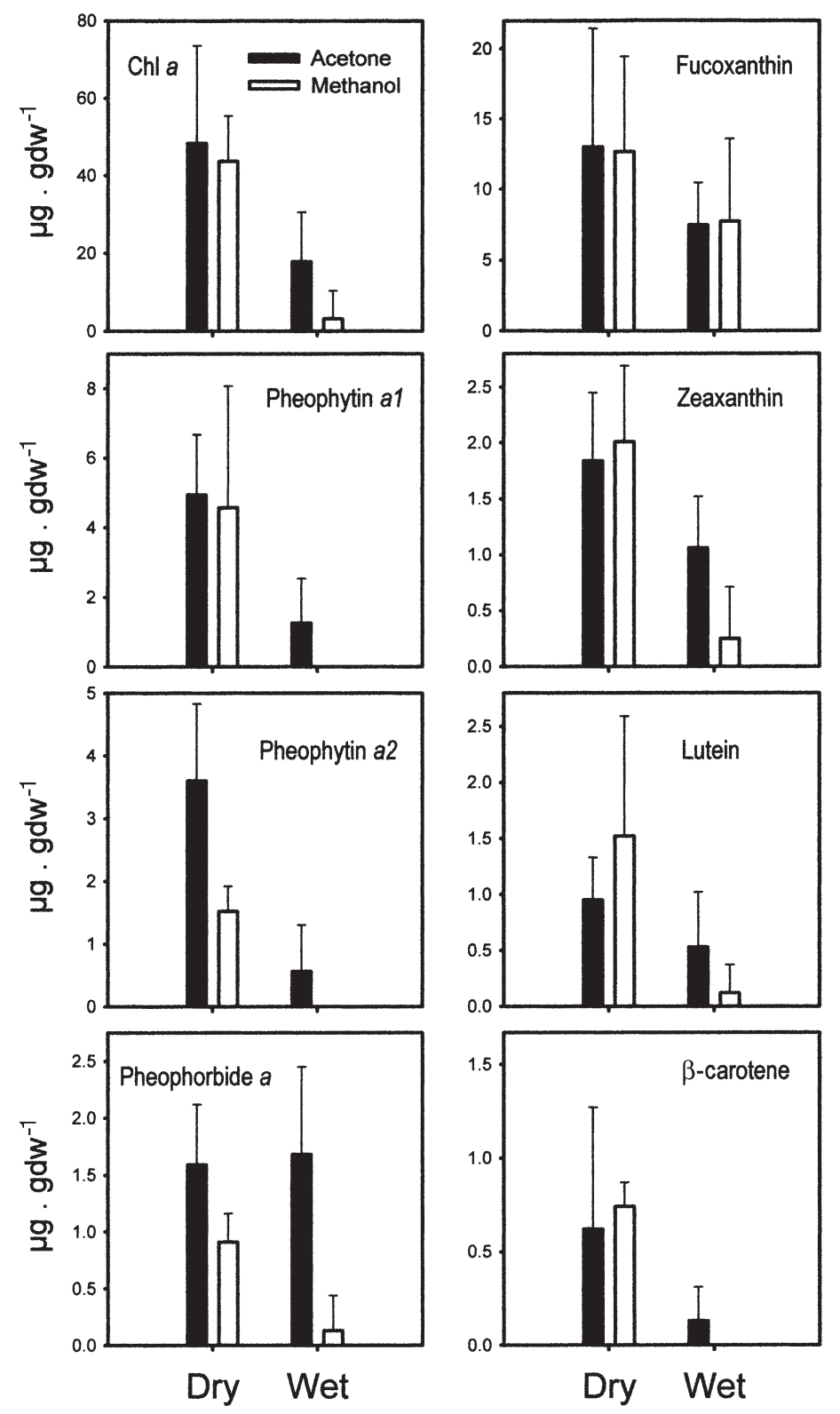

Fig. 1. Average pigment concentrations in superficial sediment (top $1 \mathrm{~cm}$ ) determined from freeze-dried (Dry) and nonfreeze-dried (Wet) samples extracted in 100\% acetone and buffered methanol. Concentrations are normalized for sediment dry weight. Error bars are \pm 1 SD $(n=6)$ the study site, sample collection and preservation, as well as the liquid chromatograph and the HPLC analysis procedure (Wright et al. 1991) to determine benthic microalgal pigment concentrations, are described in Buffan-Dubau \& Carman (2000). During analysis of the extraction-duration test, pheophorbide $a$ was not properly detected with our system, thus we have no data on pheophorbide $a$ concerning the extraction-duration test.

Extraction efficiencies of methanol versus acetone solvents, and the influence of freeze-drying were tested using sediment from 6 replicate cores. Sediment from each core was homogenized and divided into 4 subsamples $(0.50 \pm 0.13 \mathrm{~g}$ dry weight $)$ and frozen at $-80^{\circ} \mathrm{C}$. Two subsamples from each core were freezedried. One of the freeze-dried and one of the nonfreeze-dried samples from each core were extracted in acetone, and the remaining samples were extracted in methanol. Pigments were extracted by sonicating for $30 \mathrm{~s}$ in either $5 \mathrm{ml} 100 \%$ cold acetone or $5 \mathrm{ml}$ cold buffered methanol ( $2 \% \quad 0.5 \mathrm{M}$ ammonium acetate; Wright et al. 1991) and incubating overnight in the dark at $-20^{\circ} \mathrm{C}$. Extracts were then separated from sediment by centrifugation, filtered (Corning $0.2 \mu \mathrm{m}$ ), and stored in the dark at $-80^{\circ} \mathrm{C}$ under nitrogen gas atmosphere. Immediately before HPLC analysis, extracts were diluted with water (Mallinckrodt, HPLC quality) to $70 \%$ acetone or $80 \%$ methanol to improve the sharpness of peaks (Wright et al. 1991). One hundred $\mu \mathrm{l}$ of each diluted extract was analysed by HPLC within $24 \mathrm{~h}$ following extraction.

Effects of varied extraction durations were tested using frozen superficial sediment (top $1 \mathrm{~cm}$ ) partitioned in 3 subsamples ( 0.63 to $0.66 \mathrm{~g}$ dry weight) and freeze-dried. Pigments were extracted by sonicating each subsample for $30 \mathrm{~s}$ in $15 \mathrm{ml} 100 \%$ cold acetone and incubating for $24 \mathrm{~h}$ in the dark at $-20^{\circ} \mathrm{C}$. During the $24 \mathrm{~h}$ incubation, extracts were sampled at $3,6,12$, and $24 \mathrm{~h}$, by collecting $1 \mathrm{ml}$ aliquots, which were then analysed as described above.

Data were analysed using Sigmastat 2.03 and SysStat software. Three-way analysis of variance (ANOVA) (core, drying, and solvent) was used to analyze the influence of freeze-drying and acetone versus methanol. One-way ANOVA was used to determine the influence of extraction period on pigment recovery. When data did not meet the assumption of these statistical tests, transformation was applied (logarithmic for pigment concentrations and arcsine-square root for ratios). A posteriori comparisons were performed using Tukey's multiple-comparison test.

Results and discussion. With the exceptions of pheophorbide $a$ and fucoxanthin, pigment recoveries were significantly higher in freeze-dried than in non-freezedried sediments (Fig. 1, Table 1). Relative to the average of non-freeze-dried treatment, pre-freeze-drying of 
sediment increased chl a recovery by a factor of 2.7 and 13.7 in acetone and methanol extracts, respectively (Table 2). A similar trend was observed in all other pigments with the exception of pheophorbide a (Table 2). Extraction of non-freeze-dried sediment in methanol was least efficient; it yielded no pheophytin (a1 or a2) or $\beta$-carotene, and, with the exception of fuxocanthin, concentrations of all other pigments were low (Fig. 1). Water content of wet samples induced solvent dilution to unknown extents. It is likely that these uncontrolled dilutions reduced both solvation and penetration properties of the extraction solvent in wet samples.

The choice of extract solvent had a less dramatic influence on pigment recoveries than did freeze-drying (Fig. 1). Pheophytin a2 and pheophorbide $a$ were recovered in significantly greater concentrations in acetone than in methanol extracts (Table 1); acetone extracts contained approximately twice as much of these pigments relative to methanol extracts (Table 2). In freeze-dried sediments, methanol and acetone extracts yielded similar concentrations of chl $a$, pheophytin a1, fucoxanthin, and zeaxanthin (Tables 1 \& 2). Lutein and $\beta$-carotene recoveries were greater (though not significantly) in methanol (Tables 1 \& 2). Overall, total pigment concentration recovered in the acetone extraction $\left(75.9 \pm 37.5 \mathrm{SD} \mu \mathrm{g} \mathrm{g}^{-1}\right)$ was similar to total pigments recovered in methanol $\left(77.5 \pm 20.7{\mu g^{-1}}^{-1}\right)$. Jeffrey et al. (1997) compared the efficiency of different protocols that have been reported in the literature.

Table 1. Results of 3-way ANOVA (water content, solvent, and core) on the extraction efficiency of pigments. Neither the 'core' factor, nor any interaction terms associated with 'core' were significant ( $p>0.05)$. Thus significant influences of water content and solvent (and their interaction) are shown. $\mathrm{ns}=$ not significant, $\mathrm{Ac}=$ acetone, $\mathrm{MeOH}=$ methanol . Data are illustrated in Fig. 1

\begin{tabular}{|c|c|c|c|}
\hline Pigment & Water & Solvent & Interaction \\
\hline Chl a & $\begin{array}{l}\text { Dry }>\text { Wet } \\
p<0.001\end{array}$ & ns & ns \\
\hline Pheophytin a1 & $\begin{array}{l}\text { Dry }>\text { Wet } \\
p<0.001\end{array}$ & ns & ns \\
\hline Pheophytin a2 & $\begin{array}{l}\text { Dry }>\text { Wet } \\
p<0.001\end{array}$ & $\begin{array}{l}\mathrm{Ac}>\mathrm{MeOH} \\
\mathrm{p}<0.001\end{array}$ & $\mathrm{p}=0.021$ \\
\hline Pheophorbide $a$ & ns & $\begin{array}{l}\mathrm{Ac}>\mathrm{MeOH} \\
\mathrm{p}<0.001\end{array}$ & ns \\
\hline Fucoxanthin & ns & $\mathrm{ns}$ & $\mathrm{ns}$ \\
\hline Zeaxanthin & $\begin{array}{l}\text { Dry }>\text { Wet } \\
p<0.001\end{array}$ & ns & $\mathrm{p}=0.045$ \\
\hline Lutein & $\begin{array}{l}\text { Dry }>\text { Wet } \\
p=0.002\end{array}$ & ns & ns \\
\hline$\beta$-carotene & $\begin{array}{l}\text { Dry }>\text { Wet } \\
p<0.001\end{array}$ & ns & ns \\
\hline
\end{tabular}

Among these protocols, efficiencies of sonication in $100 \%$ acetone and in buffered methanol were compared for extraction of total pigments from 3 phytoplanktonic microalgal cultures, which are particularly difficult to extract. Methanol treatment produced the best recoveries while acetone treatment underestimation was $13 \%$ for Phaeodactylum tricornutum (diatom), $20 \%$ for Tetraselmis suecica, and $63 \%$ for Nannochloris atomus (chlorophyte). Because protocols were tested on microalgal cultures, Jeffrey et al. (1997) considered pheopigments only as markers for chl a degradation induced by extraction procedures. In our analysis of freeze-dried natural sediment, total pigments other than pheopigments (chl $a$, fucoxanthin, lutein, zeaxanthin, and $\beta$-carotene) were recovered in similar quantities from acetone $\left(64.8 \pm 34.6 \mathrm{\mu g} \mathrm{g}^{-1}\right)$ and metha-

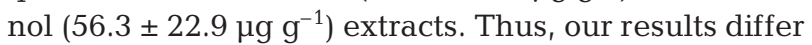
from those of Jeffrey et al. (1997), possibly as a consequence of differences in the nature of the analyzed samples (pure cultures vs a complex mixture of algae in a sediment matrix).

In freeze-dried sediments, total pheopigment (pheophytins $a$ and pheophorbides a) recovery, however, was greater in acetone $\left(10.1 \pm 3.3 \mu \mathrm{g} \mathrm{g}^{-1}\right)$ than in methanol $\left(7.0 \pm 4.0 \mathrm{\mu g} \mathrm{g}^{-1}\right)$. Chl a recovery was also slightly higher in acetone $\left(48.3 \pm 25.2 \mu \mathrm{g} \mathrm{g}^{-1}\right)$ than in methanol $\left(43.6 \pm 11.7 \mu \mathrm{g} \mathrm{g}^{-1}\right)$. This indicates that increases in pheopigment concentrations obtained with acetonic treatment did not originate from the

Table 2. Ratios of average pigment concentrations (data from Fig. 1) in all combinations of 2 solvents (acetone [Ac] and methanol $[\mathrm{MeOH}]$ ), and for freeze-dried versus non-freezedried sediments. ${ }^{*}$ No pigment recovered in non-freeze-dried methanol extractions

\begin{tabular}{|lrccc|}
\hline \multirow{2}{*}{ Pigment } & \multicolumn{4}{c}{ Ratio of concentrations } \\
& & Dry:Wet & Ac:MeOH \\
\hline Chl a & Ac & 2.7 & Dry & 1.1 \\
& MeOH & 13.7 & Wet & 5.6 \\
Pheophytin a1 & Ac & 3.9 & Dry & 1.1 \\
& $\mathrm{MeOH}$ & ${ }^{*}$ & Wet & ${ }^{*}$ \\
Pheophytin $a 2$ & $\mathrm{Ac}$ & 6.5 & Dry & 2.4 \\
& $\mathrm{MeOH}$ & ${ }^{*}$ & Wet & ${ }^{*}$ \\
Pheophorbide $a$ & $\mathrm{Ac}$ & 0.95 & Dry & 1.8 \\
& $\mathrm{MeOH}$ & 6.8 & Wet & 12.5 \\
Fucoxanthin & $\mathrm{Ac}$ & 1.7 & Dry & 1.0 \\
& $\mathrm{MeOH}$ & 1.6 & Wet & 1.0 \\
Zeaxanthin & $\mathrm{Ac}$ & 1.7 & Dry & 0.9 \\
& $\mathrm{MeOH}$ & 8.2 & Wet & 4.3 \\
Lutein & $\mathrm{Ac}$ & 1.8 & Dry & 0.6 \\
& $\mathrm{MeOH}$ & 12.6 & Wet & 4.4 \\
$\beta$-carotene & $\mathrm{Ac}$ & 4.7 & Dry & 0.8 \\
& $\mathrm{MeOH}$ & $*$ & Wet & ${ }^{*}$ \\
\hline
\end{tabular}


Table 3. Sediment pigment concentrations (mean $\pm 1 \mathrm{SD}, \mathrm{n}=3$ ) obtained over a range of extraction periods in acetone $(3,6,12$, and $24 \mathrm{~h}$ ), and 1-way ANOVAs of pigment concentrations versus times of incubation (a posterori test is Tukey's)

\begin{tabular}{|c|c|c|c|c|c|}
\hline \multirow[t]{2}{*}{ Pigment } & \multicolumn{4}{|c|}{ Concentration $\left(\mu \mathrm{g} \mathrm{g}^{-1} \mathrm{dw}\right)$} & \multirow{2}{*}{$\begin{array}{c}\text { ANOVA } \\
\mathrm{p}\end{array}$} \\
\hline & $3 \mathrm{~h}$ & $6 \mathrm{~h}$ & $12 \mathrm{~h}$ & $24 \mathrm{~h}$ & \\
\hline Chl a & $43.0 \pm 3.7$ & $41.1 \pm 3.3$ & $44.0 \pm 3.4$ & $51.6 \pm 1.0$ & $\begin{array}{c}0.01 \\
(24 \mathrm{~h}>6 \mathrm{~h}, 24 \mathrm{~h}>3 \mathrm{~h})\end{array}$ \\
\hline Fucoxanthin & $33.2 \pm 2.6$ & $31.8 \pm 5.5$ & $33.2 \pm 1.6$ & $34.9 \pm 0.5$ & 0.69 \\
\hline Diadinoxanthin & $8.8 \pm 0.7$ & $8.7 \pm 1.4$ & $8.6 \pm 0.4$ & $9.3 \pm 0.4$ & 0.68 \\
\hline Lutein & $1.4 \pm 0.1$ & $1.3 \pm 0.3$ & $1.8 \pm 0.9$ & $1.6 \pm 0.2$ & 0.60 \\
\hline Zeaxanthin & $0.7 \pm 0.03$ & $0.6 \pm 0.1$ & $0.9 \pm 0.4$ & $0.7 \pm 0.05$ & 0.58 \\
\hline$\beta$-carotene & $1.1 \pm 0.1$ & $1.0 \pm 0.2$ & $1.1 \pm 0.1$ & $1.2 \pm 0.04$ & 0.61 \\
\hline Pheophytin a1 & $6.8 \pm 0.4$ & $6.2 \pm 1.0$ & $6.2 \pm 30.4$ & $6.9 \pm 0.4$ & 0.37 \\
\hline Pheophytin a2 & $4.3 \pm 0.4$ & $4.0 \pm 0.5$ & $4.3 \pm 0.8$ & $4.2 \pm 0.2$ & 0.82 \\
\hline
\end{tabular}

degradation of chl a induced by the extraction procedure, but rather were the result of better extractability of in situ pheopigments from sediment samples. The determination of sedimentary pheopigment composition is generally needed for ecological studies of benthic communities; e.g. chl a/pheopigments a ratio is an indicator of the physiological state of the microphytobentos and pheophorbides a are considered as markers for in situ grazing activities (Bianchi et al. 1988, 1991). More generally, the study of benthic pheopigment composition is considered as a useful way for investigating the trophic dynamics of natural systems (Bianchi et al. 1991, Brotas \& Plante-Cunny 1998). Our results showed that the use of methanol as an extraction solvent may underestimate pheopigment concentrations as well as chl a concentrations in benthic field samples. Thus, we do not recommend extraction of sedimentary pigments in methanol prior to HPLC analyses.

The length of extraction significantly influenced recovery of chl a only (Table 3 ). Recovery of chl a after $24 \mathrm{~h}$ of extraction was $18 \%$ greater than after $6 \mathrm{~h}$ of extraction (Table 3). We do not know why the duration of extraction enhanced chl a recovery rate. However, it is known that the type of algal cells present influences extraction efficiency (Jeffrey et al. 1997). Some benthic diatoms are among the algae known to be difficult to extract. We know that the microphytobenthic communities in this study were dominated by diatoms (Buffan-Dubau \& Carman 2000). It is therefore likely that our samples contained a proportion of such difficult-toextract diatoms, and influenced the results concerning extraction time for chl a.

In conclusion, our results indicate that the most reliable extraction method for muddy samples should include freeze-drying of samples prior to extraction in $100 \%$ acetone. When sonication is applied, long-duration ( $>3 \mathrm{~h}$ ) extractions of samples in the solvent are not required to reliably determine concentrations of major sedimentary pigments other than chl $a$.
Acknowledgements. T. Bianchi provided HPLC standards. This research was supported by a grant from the Office of Naval Research, USA.

\section{LITERATURE CITED}

Bianchi TS, Dawson R, Sawangwong P (1988) The effect of macrobenthic deposit-feeding on the degradation of chloropigments in sandy sediments. J Exp Mar Biol Ecol 122:243-255

Bianchi TS, Findlay S, Fontvieille D (1991) Experimental degradation of plant materials in Hudson River sediments. I. Heterotrophic transformations of plant pigments. Biogeochemistry 12:171-187

Brotas V, Plante-Cunny MR (1996) Identification et quantification des pigments chlorophylliens et caroténoïdes des sédiments marins: un protocole d'analyse par HPLC. Oceanol Acta 19:623-634

Brotas V, Plante-Cunny MR (1998) Spatial and temporal patterns of microphytobenthic taxa of estuarine tidal flats in the Tagus Estuary (Portugal) using pigment analysis by HPLC. Mar Ecol Prog Ser 171:43-57

Buffan-Dubau E, Carman KR (2000) Diel feeding behavior of meiofauna and their relationships with microalgal resources. Limnol Oceanogr 45:381-395

Buffan-Dubau E, de Wit R, Castel J (1996) Feeding selectivity of the harpacticoid copepod Canuella perplexa in benthic muddy environments demonstrated by HPLC analyses of chlorin and carotenoid pigments. Mar Ecol Prog Ser 137: 71-82

Cariou-Le Gall V, Blanchard GF (1995) Monthly HPLC measurements of pigment concentration from an intertidal muddy sediment of Marennes-Oléron Bay, France. Mar Ecol Prog Ser 121:171-179

Jeffrey SW, Mantoura RFC, Wright SW (1997) Phytoplankton pigments in oceanography: guidelines to modern methods. UNESCO, Paris

Lucas CH, Holligan PM (1999) Nature and ecological implications of algal pigment diversity on the Molenplaat tidal flat (Westerschelde estuary, SW Netherlands). Mar Ecol Prog Ser 180:51-64

Paterson DM, Wiltshire KH, Miles A, Blackburn J, Davidson I, Yates MG, McGrorty S, Eastwood JA (1998) Microbiological mediation of spectral reflectance from intertidal cohesive sediments. Limnol Oceanogr 43:1207-1221

Pinckney J, Papa R, Zingmark R (1994) Comparison of highperformance liquid chromatographic, spectrophotometric, 
and fluorometric methods for determining chlorophyll a concentrations in estuarine sediments. J Microbiol Methods 19:59-66

Plante-Cunny MR, Barranguet C, Bonin D, Grenz C (1993) Does chlorophyllide a reduce reliability of chlorophyll a measurements in marine coastal sediments? Aquat Sci 55:19-30

Riaux-Gobin C, Llewellyn CA, Klein B (1987) Microphytobenthos from two subtidal sediments from North Brittany. II.

Editorial responsibility: Otto Kinne (Editor),

Oldendorf/Luhe, Germany
Variations of pigment compositions and concentrations determined by HPLC and conventional techniques. Mar Ecol Prog Ser 40:275-283

Wright SW, Jeffrey SW, Mantoura RFC, Llewellyn CA, Bjørnland T, Repeta D, Welschmeyer N (1991) Improved HPLC method for the analysis of chlorophylls and carotenoids from marine phytoplankton. Mar Ecol Prog Ser 77: 183-196

Submitted: December 30, 1999; Accepted: July 18, 2000 Proofs received from author(s): September 15, 2000 